\title{
Factors Associated with Anemia among Selected Women of Reproductive Age in Tondo, Manila, Philippines
}

\author{
Ana Kriselda B. Rivera, ${ }^{1}$ Ernani R. Bullecer ${ }^{1}$ and Angelica Anne E. Latorre ${ }^{2}$ \\ ${ }^{1}$ Department of Nutrition, College of Public Health, University of the Philippines Manila \\ ${ }^{2}$ Department of Epidemiology and Biostatistics, College of Public Health, University of the Philippines Manila
}

\begin{abstract}
Background. Anemia is the most common medical disorder throughout a woman's life. Given that anemia during reproductive years impacts future gestational and perinatal health, then any factors possibly associated with the disorder should be studied and ultimately addressed.

Objective. This study aimed to determine anemia prevalence and its associated factors (socio-demographic, lifestyle, knowledge, dietary and biochemical) among a select group of women of reproductive age (WRA) living in Tondo, Manila.
\end{abstract}

Methods. This is an analytic cross-sectional study that utilized interviewer-assisted questionnaire and blood extraction to collect data from 166 WRA (18-40 years).

Results. Anemia prevalence among the study participants was found to be $9.0 \%$. In terms of associated factors, being anemic was found to be more likely if the WRA has these factors: higher parity, graduated from college; unemployed; living in a low-income household; took iron supplements, and; have low knowledge on iron. On the other hand, increase in age, increase intake of heme iron and non-heme iron food sources, and an increase in blood ferritin concentration were factors that made anemia less likely among WRA.

Conclusion. Examining these factors provides insight into the multicausal nature of anemia. Thus, prevention and control programs should focus on the contribution and interrelatedness of these factors to address anemia.

Key Words: anemia, hemoglobin, iron, women of reproductive age

\section{INTRODUCTION}

Corresponding author: Ana Kriselda B. Rivera, RMT, MPH Department of Nutrition College of Public Health University of the Philippines Manila 625 Pedro Gil St., Ermita, Manila 1000, Philippines Email: abrivera3@up.edu.ph
A healthy woman in her reproductive years establishes a foundation for an equally healthy maternal and infant health. Ideally, a woman who is planning to conceive prepares herself for the requirements pregnancy will demand. Not enough nourishment during the reproductive years raises a woman's risk for gestational and perinatal problems in the future. Furthermore, the health of a woman in her reproductive years has a direct impact on the chances of survival of a newborn child and can be applied as an indicator of perinatal health. ${ }^{1}$

Anemia refers to a condition wherein there is an insufficient number of red blood cells in the body, thus, also limiting its oxygen-carrying capacity. Age, gender, altitude, smoking behavior, and pregnancy affect the body's demand for red blood cells and oxygen. The causes of anemia are nutritional deficiencies, acute and chronic inflammation, 
parasitic infections and inherited blood disorders. Among all of these, the deficiency of iron in the body is known to be the most common cause of anemia. ${ }^{2}$

In 2016, it was estimated that among all women of reproductive age (WRA) (\% of women ages 15-49) in the world, $32.8 \%$ are anemic. The last time global data reached this high proportion was in 1998 with a prevalence of $32.5 \% .^{3}$ Global trend shows that anemia prevalence has been rising again for all women regardless of physiological state.

On the contrary, Philippine data reveals a slow but steady fall in anemia prevalence among WRA since the '90s. Even so, anemia in WRA remains to be of public health significance in the country. In 2015, the national prevalence of anemia was $15.7 \%$ among WRA. ${ }^{3}$ While the most recent Expanded National Nutrition Survey (ENNS) found that the prevalence of anemia among WRA in the country is $11.6 \%$ in 2018 . This prevalence remains virtually the same across the wealth quintiles, and among urban and rural places as well. Unfortunately, there is no data on the correlation between risk factors and anemia. ${ }^{4}$

Due to physiological vulnerability, children under 5 years and WRA are considered high risk for anemia. ${ }^{5}$ WRA are particularly at risk of anemia because of biological conditions inherent to the group such as menstruation and pregnancy. Thus, women who are already anemic prior to pregnancy increase their risk for maternal anemia which results in more complications for both mother and fetus. ${ }^{6}$

Three immediate causes of anemia are inadequate nutrient intake and absorption, genetic hemoglobin disorders (sickle-cell disorders and thalassemias), and exposure and response to infectious disease. Poor nutrition and infections are consequences of multifactorial determinants of health. The complex interplay of political, ecological, social and biological factors leading to anemia has been a challenge to prevention and control efforts 5 , highlighting the need to continually understand its relations to better address context-specific predictors of anemia. With these reasons, the following study objectives were aimed: first, determine the prevalence of anemia among selected WRA living in Tondo, Manila; second, compare the socio-demographic (age, parity, educational attainment, employment status, monthly family income), lifestyle (iron supplement use), knowledge (knowledge on anemia and knowledge on iron), dietary (heme, non-heme and total iron intake), and biochemical (ferritin) factors of WRA by anemia status; and lastly, describe the association of anemia with the aforementioned factors among the anemic WRA.

\section{MATERIALS AND METHODS}

\section{Study Design and Sampling}

The study utilized an analytic cross-sectional study design. Recruitment of participants was held in ten health centers scattered across Tondo Districts 1 and 2. This study employed a convenience sampling design among women who visited the health center for different reasons.

\section{Study Area}

Tondo comprised of two large districts of Manila and is home to people of diverse socio-economic backgrounds. It is situated in the National Capital Region (NCR) where there is high anemia prevalence across all age groups. ${ }^{7}$ Hence, Tondo continues to be the focus of several nutritional programs of government and non-governmental organizations in order to address these problems.

\section{Inclusion and Exclusion Criteria}

Women were approached and invited to participate provided they satisfy the inclusion criteria of being between the ages of 18 and 44, and currently living in Tondo, Manila. Those who gave their consent to participate were included in the study. Meanwhile, women who self-reported to have any of the following conditions are excluded in the study: ongoing medical conditions (such as diabetes, hypertension, cancers, etc.), currently taking therapeutic or prescription drugs (except vitamins or supplements), or are pregnant or probably pregnant (as determined by last menstrual period).

\section{Data Collection}

Data from participants were collected using an interviewer-assisted questionnaire and blood extraction. Blood samples were collected from participants and were analyzed for hemoglobin concentration at the Philippine General Hospital laboratories. Hemoglobin measurements were done to identify the presence of anemia. The prevalence and severity of anemia in a population is an important health indicator. According to WHO cut-offs, the normal hemoglobin concentration is $120.0 \mu \mathrm{g} / \mathrm{L}$ or higher and any value lower than that is categorized as having anemia. ${ }^{2}$ Likewise, blood ferritin concentration was used to check for adequacy of iron stores in the body. Ferritin is a protein that has an important role in the storage of intracellular iron and is considered the most specific biochemical marker for iron stores. ${ }^{8,9}$ Ferritin is the test of choice for detecting iron deficiency anemia in the 2013 National Nutrition Survey (NNS). A serum ferritin level of less than $12 \mu \mathrm{g} / \mathrm{L}$ is universally accepted as an indication of depleted iron stores, while a concentration of $>200 \mu \mathrm{g} / \mathrm{L}$ implies a severe risk for iron overload. ${ }^{9}$

Aside from blood samples, pertinent information was obtained through a 4-part questionnaire administered by a registered nutritionist-dietitian (RND). The data collection tool covered the participant's socio-demographic profile (age, parity, educational attainment, employment status, and monthly family income). This was followed by a lifestyle factor that is mainly ever used for pure iron supplementation.

The next part covered the participant's knowledge of iron and anemia. The participants were asked to answer a short 
Factors Associated with Anemia

quiz to test their knowledge. The quiz comprised of two sets of ten 'True or False' questions respectively relating to anemia and iron facts. A score of 0-4 for a set suggested low knowledge, while 5-10 was high knowledge. For the first set, almost all participants had a high knowledge of anemia.

The last part was the dietary factor which involved the use of a semi-quantitative food frequency questionnaire (SFFQ), a suitable estimator of individual micro-nutrient intake. Since this study was focused on anemia, then iron consumption of WRAs was evaluated. One advantage of the FFQ was its ability to measure the consumption of specific nutrients of a population group which makes it a common tool used in epidemiological studies on dietary patterns (International Dietary Data Expansion). Although the FFQ relies on a longer recall period (usually up to one month), it nevertheless provides a more "usual intake" of food items as compared to other dietary assessment tools. ${ }^{10}$ This study adopted the Philippines Semi-Quantitative Food Frequency Questionnaire (SFFQ) utilized by the Prospective Urban and Rural Epidemiological (PURE) Study of the Population Health Research Institute (PHRI) in Canada. Only the food items with iron content based on the Philippine Food Composition Tables ${ }^{11}$ were retained and later grouped into heme iron and non-heme iron sources. Heme iron was assessed from all meat sources (beef, pork, etc.) including fish, chicken, and bagoong (shrimp paste). Plant foods were sources of non-heme iron. The study variables for the dietary factor comprised of heme iron, non-heme iron and total iron intakes (all units are in milligrams).

\section{Data Analysis}

Data analysis was performed using Stata $14 \mathrm{SE}$ for Mac software. The prevalence of anemic WRA was computed, as well as the descriptive statistics which were used to describe the characteristics of non-anemic and anemic WRA. The means and standard deviations were provided for continuous variables while frequencies and percentages were given for categorical variables. Multiple logistic regression was used to describe the association of socio-demographic, lifestyle, knowledge, dietary and biochemical factors with anemia. Odds ratio (adjusted and unadjusted) were given; however, $\mathrm{p}$-values and confidence intervals were not presented because the results were not intended to be generalized outside the study population.

\section{Ethical Considerations}

The protocol of this study received approval from the University of the Philippines Manila Research Ethics Board (UPM REB). Written consent in Tagalog was obtained from all participating women. The consent form briefed the participant about the purpose of the study, data collection procedure, possible risks and known benefits of participating, voluntary participation, and data privacy and anonymity.

\section{RESULTS}

\section{Profile of participants}

Table 1 presented the profile of the participants. The values for the factors are given in frequency and percentages or $\mathrm{n}(\%)$ for the categorical variables; and mean and standard deviations or Mean $\pm \mathrm{SD}$ for the continuous variables.

A total of 166 WRA were recruited as study participants. From the results of the hemoglobin test, it was found that only 9.0\% (15 out of 166) of them were anemic ( $\mathrm{Hgb}<120$ $\mu \mathrm{g} / \mathrm{L})$. This proportion is lower than the anemia prevalence of $11.6 \%$ among WRA from the 2018 ENNS. ${ }^{4}$ The mean age was 29.8 years with a mean of two births. Most of them finished high school education only (60.2\%) and were currently unemployed (63.9\%) at the time of the interview. The majority belonged to a family with an average monthly income ranging from Php 7,891 to 15,780 (38.0\%), followed

Table 1. Profile of the participants $(n=166)$

\begin{tabular}{lc}
\multicolumn{1}{c}{ Variables } & $\mathbf{n}(\%)$ or \\
Mean \pm SD
\end{tabular}


by those with the lowest monthly income of Php 7,890 or less (32.5\%).

Most of the participants (77.1\%) reported that they have taken iron supplements at least once in their life. In terms of knowledge, almost all of them have high knowledge of anemia (99.4\%) and iron (92.2\%). Dietary data showed that the participants had lower $(19.7 \mathrm{mg})$ than the daily recommended iron intake, with most of this quantity (17.2 $\mathrm{mg}$ ) coming from foods with the non-heme iron component which takes longer to digest. But, in general, their mean iron stores $(58.5 \mu \mathrm{g} / \mathrm{L})$ still indicated an adequate supply of the mineral in the body.

\section{Description of factors by anemia status}

The general characteristics of the non-anemic and anemic WRA were summarized in two tables. Table 2.1 presented data for the continuous variables which were: age and parity (socio-demographic); heme, non-heme and total iron (dietary); and ferritin (biochemical). While Table 2.2 presented data for the following categorical variables: educational attainment, employment status, average monthly family income (socio-demographic); iron supplement use (lifestyle); and knowledge on anemia and iron (knowledge).

As for educational attainment, most of non-anemic $(61.6 \%)$ and anemic (46.7\%) WRA reported having finished high school education only. Meanwhile, for the
Table 2.1. Description of factors of selected WRA by anemia status $(n=166)$

\begin{tabular}{lccc} 
& \multicolumn{2}{c}{ Anemia Status } & Total \\
\cline { 2 - 3 } \multicolumn{1}{c}{ Variables } & $\begin{array}{c}\text { Non-anemic } \\
(\mathbf{n}=\mathbf{1 5 1}) \\
\text { Mean } \pm \text { SD }\end{array}$ & $\begin{array}{c}\text { Anemic } \\
(\mathbf{n}=15) \\
\text { Mean } \pm \text { SD }\end{array}$ & $\begin{array}{c}(\mathbf{n}=166) \\
\text { Mean } \pm \text { SD }\end{array}$ \\
\hline $\begin{array}{c}\text { Socio-demographic } \\
\quad \text { Age (years) }\end{array}$ & $29.8 \pm 6.6$ & $29.3 \pm 6.9$ & $29.8 \pm 6.6$ \\
$\quad$ Parity (births) & $2.2 \pm 1.6$ & $2.4 \pm 1.6$ & $2.2 \pm 1.6$ \\
\hline Dietary & & & \\
$\quad$ Heme iron (mg) & $2.5 \pm 2.7$ & $2.2 \pm 1.7$ & $2.5 \pm 2.6$ \\
$\quad$ Non-heme iron (mg) & $17.2 \pm 8.7$ & $16.4 \pm 9.3$ & $17.2 \pm 8.7$ \\
$\quad$ Total iron (mg) & $19.7 \pm 9.7$ & $19.0 \pm 10.0$ & $19.7 \pm 9.7$ \\
\hline Biochemical & & & \\
$\quad$ Ferritin $(\mu \mathrm{g} / \mathrm{L})$ & $59.2 \pm 53.2$ & $52.2 \pm 53.4$ & $58.5 \pm 53.0$ \\
\hline
\end{tabular}

status of employment, the study found that the majority of non-anemic (63.6\%) and anemic (66.7\%) WRA were currently unemployed at the time of data collection. In terms of average monthly family income, most (40.0\%) anemic WRA belonged to a family with an average monthly income of Php 7,890 or lower. Whereas, an average monthly family income ranging from Php 7,891 to Php 15,780 was commonly reported by non-anemic WRA (39.1\%).

Intake of iron supplements is the only lifestyle factor included in the study. The participants were asked if they

Table 2.2. Description of factors of selected WRA by anemia status $(n=166)$

\begin{tabular}{|c|c|c|c|}
\hline \multirow[b]{2}{*}{ Variables } & \multicolumn{2}{|c|}{ Anemia Status } & \multirow[b]{2}{*}{$\begin{array}{c}\text { Total } \\
(n=166) \\
n(\%)\end{array}$} \\
\hline & $\begin{array}{c}\text { Non-anemic } \\
(\mathrm{n}=151) \\
\mathrm{n}(\%)\end{array}$ & $\begin{array}{c}\text { Anemic } \\
(n=15) \\
n(\%)\end{array}$ & \\
\hline \multicolumn{4}{|l|}{ Socio-demographic } \\
\hline \multicolumn{4}{|l|}{ Educational attainment } \\
\hline No formal education and elementary education & $23(15.2)$ & $3(20.0)$ & $26(15.7)$ \\
\hline High school & $93(61.6)$ & $7(46.7)$ & $100(60.2)$ \\
\hline College & $35(23.2)$ & $5(33.3)$ & $40(24.1)$ \\
\hline \multicolumn{4}{|l|}{ Employment status } \\
\hline Employed & $55(36.4)$ & $5(33.3)$ & $60(36.1)$ \\
\hline Unemployed & $96(63.6)$ & $10(66.7)$ & $106(63.9)$ \\
\hline \multicolumn{4}{|l|}{ Average monthly family income (Php) } \\
\hline 7,890 and below & $48(31.8)$ & $6(40.0)$ & $54(32.5)$ \\
\hline 7,891 to 15,780 & $59(39.1)$ & $4(26.7)$ & $63(38.0)$ \\
\hline 15,780 to 31,560 & $25(16.6)$ & $4(26.7)$ & $29(17.5)$ \\
\hline Above 31,560 & $19(12.6)$ & $1(6.7)$ & $20(12.0)$ \\
\hline \multicolumn{4}{|l|}{ Lifestyle } \\
\hline \multicolumn{4}{|l|}{ Iron supplement use } \\
\hline Ever taken & $117(77.5)$ & $11(73.3)$ & $128(77.1)$ \\
\hline Never taken & $34(22.5)$ & $4(26.7)$ & $38(22.9)$ \\
\hline \multicolumn{4}{|l|}{ Knowledge } \\
\hline \multicolumn{4}{|l|}{ Knowledge on anemia } \\
\hline High & $150(99.3)$ & $15(100.0)$ & $165(99.4)$ \\
\hline Low & $1(0.7)$ & $0(0.0)$ & $1(0.6)$ \\
\hline \multicolumn{4}{|l|}{ Knowledge on iron } \\
\hline High & 140 (92.7) & $13(86.7)$ & $153(92.2)$ \\
\hline Low & $11(7.3)$ & $2(13.3)$ & $13(7.8)$ \\
\hline
\end{tabular}


were presently taking or took iron supplements before; otherwise, they were categorized as the 'never taken' group. The majority of non-anemic (76.8\%) and anemic (73.3\%) WRA said they took iron supplements at least once in their life.

With regard to knowledge on anemia, the majority of non-anemic (99.3\%) and all anemic (100\%) WRA were found to have a high level of knowledge which means that only one non-anemic participant obtained a low score; and, remarkably, no anemic participant obtained low knowledge on anemia. After that, the participants were tested on their knowledge of the importance of iron and its food sources. The majority of non-anemic (92.7\%) and anemic (86.7\%) WRA were revealed to have high knowledge of iron as well.

\section{Factors associated with anemia}

The association of the factors with anemia are shown in Table 3. The study revealed that the odds of having anemia decreased by $0.04 \%$ for every year increase in age. In terms of parity, the anemia likelihood increases by $30.0 \%$ for every birth. Meanwhile, those who attained a college education were more likely to be anemic $(\mathrm{OR}=3.2)$ than those who graduated from high school only. College graduates were also more likely to be anemic $(\mathrm{OR}=1.79)$ than those with no education or who finished elementary education only. Unemployed WRA were also found to be more likely $(\mathrm{OR}=1.38)$ to be anemic than their employed counterpart. Comparing to WRA living in a household with a monthly income of > Php 31,560, some WRA belonging to smaller income brackets were twice more likely to have anemia. Those who have taken iron supplements were revealed to be more likely $(\mathrm{OR}=1.23)$ to have anemia than those who never took iron supplements. With regard to diet, the odds of having anemia decreases by $0.04 \%$ and $0.02 \%$ for every milligram consumed of heme iron and non-heme iron, respectively. Those who had low knowledge of iron were almost thrice more likely to be anemic $(\mathrm{OR}=2.90)$ than those with high knowledge of iron. Meanwhile, knowledge on anemia was excluded from the analysis since there were no anemic respondents that had low anemia knowledge. Lastly, anemia likelihood decreases by $0.01 \%$ for every unit $(\mu \mathrm{g} / \mathrm{L})$ increase of ferritin concentration in the blood.

\section{DISCUSSION}

Anemia prevalence among WRA in the country has been declining gradually since 1997 which was $37.6 \%$ at that time. ${ }^{3}$ The latest data now show the prevalence to be $11.6 \%{ }^{4}$ The anemia prevalence of WRA who participated in this study is $9.0 \%$. In any case, the lower prevalence is a welcome development as the Philippine Plan of Action for Nutrition (PPAN) targets a 6.0\% anemia prevalence among WRA by $2022 .{ }^{13}$

Unlike the other factors studied, age and parity are already established predictors of anemia. The mean age and parity of the study participants were similar to that of national figures - 30 years and two births as of 2017. ${ }^{14}$ As women age, the chances of pregnancy also increase. Frequent

Table 3. Factors associated with anemia among selected WRA

\begin{tabular}{|c|c|c|c|}
\hline Factors & Odds Ratio unadjusted & Odds Ratio adjusted & p-value \\
\hline \multicolumn{4}{|l|}{ Socio-demographic } \\
\hline Age & 0.99 & 0.96 & 0.60 \\
\hline Parity & 1.09 & 1.3 & 0.28 \\
\hline \multicolumn{4}{|l|}{ Education (Reference: College) } \\
\hline High school & 0.53 & 0.31 & 0.11 \\
\hline $\begin{array}{l}\text { No formal education and } \\
\text { elementary education }\end{array}$ & 0.91 & 0.56 & 0.55 \\
\hline \multicolumn{4}{|l|}{$\begin{array}{l}\text { Employment status } \\
\text { (Reference: Employed) }\end{array}$} \\
\hline Unemployed & 1.15 & 1.38 & 0.64 \\
\hline \multicolumn{4}{|c|}{$\begin{array}{l}\text { Monthly family income } \\
\text { (Reference: Above Php 31,560) }\end{array}$} \\
\hline 15,780 to 31,560 & 3.04 & 2.64 & 0.43 \\
\hline 7,891 to 15,780 & 1.29 & 1.22 & 0.88 \\
\hline 7,890 and below & 2.38 & 2.45 & 0.49 \\
\hline \multicolumn{4}{|l|}{ Lifestyle } \\
\hline \multicolumn{4}{|l|}{$\begin{array}{l}\text { Iron supplement use } \\
\text { (Reference: Ever taken) }\end{array}$} \\
\hline Never taken & 0.8 & 0.81 & 0.76 \\
\hline \multicolumn{4}{|l|}{ Knowledge } \\
\hline \multicolumn{4}{|c|}{ Knowledge on iron (Reference: High) } \\
\hline Low & 1.96 & 2.9 & 0.25 \\
\hline \multicolumn{4}{|l|}{ Biochemical } \\
\hline Ferritin & 0.99 & 0.99 & 0.85 \\
\hline
\end{tabular}


pregnancies with short birth intervals between children cause iron stores to deplete. ${ }^{15}$ This study found that a year increase in age decreases anemia odds by a small percentage which is opposed to present literature. The relatively low number of anemic participants might have accounted for the different associations. Nevertheless, data on parity is in accord with other references which report a positive correlation between the number of births and anemia likelihood.

It is presumed that having attained a high level of education will automatically translate to having improved health status (including nutritional status). ${ }^{16}$ As an example, one recent found that illiterate women were twice more likely to have anemia and those who only finished primary education were more likely to be anemic than those with higher educational attainment. ${ }^{17}$ Contrary to the said notion, results from this study revealed otherwise. In this study, college degree holders were more likely to be anemic than those with lower educational attainment. These findings were supported by the study of Adamu et al. which found that women who attended secondary or tertiary education had higher odds of being mildly anemic as compared to those with lower education. It was hypothesized that more educated women have shifted away from traditional diets and supplements ${ }^{15}$ perhaps due to the environment and lifestyle factors.

Education is an important indicator of development. In this regard, educational attainment influences other socio-demographic factors such as employment and income. Unemployed participants were more likely to be anemic than employed participants. Likewise, participants belonging to households with lower combined monthly income were almost twice more likely to be anemic compared to those belonging to the highest combined monthly income bracket. Unemployed WRA belonging to low-income households may have difficulty in accessing iron-rich foods on a regular basis, although this presumption still needs validation.

In the same way, educational attainment is important in comprehending health information. Generally, this study found that non-anemic and anemic women had high knowledge of anemia and iron. This suggests that women in the study area have been properly educated in the subject matter and that they have retained correct information. Considering that the women who participated in the study were recruited in health centers, it is logical to assume that they have been recipients of health services including health education. Nevertheless, to further improve didactic interventions, it is highly recommended to administer literacy-appropriate nutrition education. ${ }^{18}$

Interestingly, participants who reported to have taken iron supplements at least once were found to be more likely to have anemia than those who never took iron supplements. Although the reason for iron supplement use was not explored in the study. But still, this finding is inconsistent with most study findings which indicate higher anemia likelihood among non-users. Besides, iron supplements are intended to treat or reduce the risk of anemia among nonpregnant WRA. ${ }^{19}$ Again, a possible explanation for the contradicting result is the low prevalence of anemic participants which may have affected the lack of variation.

Deficiency of iron in the body is known to be the most common cause of anemia. ${ }^{2}$ Iron is mainly acquired from dietary sources. Study findings revealed that anemic participants only have an average of $19.0 \mathrm{mg}$ as daily total iron intake which is below the recommended amount of $28.0 \mathrm{mg}$. Although, experts also state that the required iron intake for WRA is not attainable by diet alone; and that, the remaining amount could be met by the use of iron supplements. ${ }^{4}$

Separately analyzing the types of iron in food, the results of the study indicate that anemic women consumed more non-heme food items which are plant-based food. Nonheme iron actually needs further metabolism before it gets absorbed in the body, unlike heme which is easily absorbed in the intestine. ${ }^{20}$ Relating the food items recorded in the SFFQ with the socio-demographic data of the participants, it is suggestive that anemia could be due to household food insecurity. Again, the majority (40\%) of the anemic women in this study belong to the lowest monthly family income bracket. Heme iron food sources such as red meat and liver are quite costly to be consumed on a regular basis especially for poor families.

In addition, the limited availability of iron-rich food can be considered as a reason for low dietary intake. A study has shown that the increased anemia prevalence in Sub-Saharan Africa, South and Southeast Asian regions was consistent with the decrease in dietary iron supply. ${ }^{5}$ The authors of the study further explained that the human diet has moved away from the hunter-gatherer type in favor of cultivated food and where heating has become an inevitable process in food preparation. Modern food preparations have resulted in a decrease in the bioavailability of nutrients such as iron, vitamin $\mathrm{B} 12$, and folic acid, as well as vitamin $\mathrm{C}$ which is a known absorption enhancer. Likewise, there has been an increase in the intake of polyphenols found in tea and coffee throughout the years - these drinks have polyphenols and phytates which counteract iron bioavailability. ${ }^{5}$

Despite inadequate dietary iron intake, results show that anemic women had an acceptable level of iron stores as defined by ferritin concentration. According to the 8th NNS, a mean ferritin level of $56.81 \mu \mathrm{g} / \mathrm{L}$ was found among adults aged $20-59$ years and that $17.9 \%$ of the population had depleted iron stores. ${ }^{9}$ A possible explanation for this subgroup is that the iron content in their blood (heme part in hemoglobin) may be low but it is not too low to warrant the utilization of stored iron (ferritin). When the body does not have enough iron that is readily available in the bloodstream, it starts to utilize stored iron to compensate for its needs.

For several years, women will have menstruations that can temporarily deplete iron as blood is excreted out of the body. Iron stores are particularly important if these women 
become pregnant in the future. A study in Spain found that $36 \%$ of women had low pre-pregnancy iron stores. ${ }^{21}$ During pregnancy, the body produces more blood to support the development of the fetus; which, in turn, also requires more iron supply. ${ }^{20}$

\section{Study limitations}

The findings of this study are only applicable to the study population and cannot be further applied to WRA in general. Respondents' past medical history and the presence of parasitic infections were not inquired. Also, ecological and behavioral factors affecting nutritional status were not included as study variables. Ecological factors such as food accessibility and availability, and healthcare service factors and other health-related practices may influence anemia status. The small number of respondents resulted in a lack of variation among the non-anemic and anemic groups which have limited the analysis and interpretation of data. Possible ecological and behavior factors not included in the study may have also affected the variability of results.

\section{CONCLUSION}

An anemia prevalence of $9.0 \%$ was determined among selected WRA living in Tondo, Manila. The following characteristics were found among most of the anemic WRA: mean age of 29 , parity of two, low dietary iron intake, normal iron stores, finished high school education only, currently unemployed, have family monthly income of $\leq$ Php 7,890, took iron supplements, and have high knowledge on anemia and iron.

In terms of associated factors, anemia was more likely among WRA who: have higher parity, were college graduates; were unemployed; belong to a low-income household; took iron supplements, and; have low knowledge of iron. On the other hand, these factors decrease anemia likelihood: increase in age; increase intake of heme iron and non-heme iron food sources; and increase in blood ferritin concentration.

Study findings also suggest that other than increased physiological vulnerability, social vulnerabilities exacerbate the health conditions of women in their reproductive years. Education, employment and income may be of less priority to women whose prime concern is child-rearing. In their paper, Balarajan et al. considered anemia as a "marker" of socioeconomic disadvantage; where, in most cases, the poorest and least educated have higher exposure to the risk factors of anemia. Indeed, the complex interplay of multifactorial causes leading to anemia has been a challenge to prevention and control efforts.

Traditional approaches such as awareness, education, and counseling have been in place for a long time. However, two decades of data reveal slow progress when it comes to lowering anemia prevalence to that of a mild public health significance category. Perhaps, more than a medical issue, anemia should be confronted as a societal and ecological issue with interventions targeting food systems and health service delivery rather than individuals.

Nutrition education is still a key intervention point. However, behavior change strategies may be more applicable at this point rather than just knowledge enhancement as seen in the results of the study. It is also recommended for behavior change strategies to encompass modifications affecting the whole life cycle instead of targeted life phases (pregnancy, lactating, etc.) ${ }^{22}$; this way, women are more inclined to shift towards behaviors they know would be beneficial for the rest of her life. To further enable behavior change, iron-rich foods should be made more available and accessible especially to poor families. Another approach is to integrate anemia and nutrition education in family planning programs. ${ }^{22}$

\section{Acknowledgment}

The authors would like to thank the assistance extended by the Manila Heath Department and Tondo Districts 1 and 2 Health Centers; as well as the help provided by Mr. Jess Adaya, Ms. Ma. Ysabel Leanne Brual, Mr. Alfred Ken Chan and Ms. Anna Paulina Sabularse.

\section{Statement of Authorship}

All authors participated in data collection and analysis, and approved the final version submitted.

\section{Author Disclosure}

All authors declared no conflicts of interest.

\section{Funding Source}

This paper was funded by the National Institutes of Health, University of the Philippines Manila.

\section{REFERENCES}

1. World Health Organization. Women of childbearing age who are malnourished [Internet]. 2017 [cited 2019 Dec 27]. Available from: https://www.who.int/ceh/indicators/malnourishedwomen.pdf

2. World Health Organization. Haemoglobin concentrations for the diagnosis of anaemia and assessment of severity [Internet]. Vitamin and Mineral Nutrition Information System. 2011 [cited 2019 Dec 19]. Available from: https://apps.who.int/iris/bitstream/ handle/10665/85839/WHO_NMH_NHD_MNM_11.1_eng.pdf

3. World Health Organization. Global Health Observatory Data Repository/World Health Statistics [Internet]. 2019 [cited 2019 Dec 27]. Available from: http://apps.who.int/gho/data/node. main.1?lang=en

4. Department of Science and Technology - Food and Nutrition Research Institute. Expanded National Nutrition Survey (ENNS) Nutritional Status of Filipino Adolescents and Women of Reproductive Age [Internet]. 2009 [cited 2019 Dec 27]. Available from: https://www. fnri.dost.gov.ph/images//sources/eNNS2018/ADOLESCENTS_ and_WRA.pdf

5. Balarajan Y, Ramakrishnan U, Özaltin E, Shankar AH, Subramanian SV.Anaemia in low-income and middle-income countries. Lancet. 2011 Dec ;378(9809):2123-35. doi.org/10.1016/S0140-6736(10)62304-5

6. Goonewardene M, Shehata M, Hamad A. Anaemia in pregnancy. Best Pract Res Clin Obstet Gynaecol. 2012 Feb; 26(1):3-24. doi. org/10.1016/j.bpobgyn.2011.10.010 
7. Department of Science and Technology - Food and Nutrition Research Institute. Philippine Nutrition Facts and Figures 2013: 8th National Nutrition Survey Overview [Internet]. FNRI Bldg., DOST Compound, Bicutan, Taguig City, Metro Manila, Philippines. 2015 [cited 2019 Dec 27]. Available from: http://enutrition.fnri.dost.gov. ph/assets/uploads/publications/Overview_8thNNS_050416.pdf

8. Wang W, Knovich MA, Coffman LG, Torti FM, Torti SV. Serum ferritin: past, present and future. Biochim Biophys Acta. 2010 Aug; 1800(8):760-9. doi.org/10.1016/j.bbagen.2010.03.011

9. Department of Science and Technology - Food and Nutrition Research Institute. 8th National Nutrition Survey Biochemical Survey [Internet]. 2015 [cited 2019 Dec 27]. Available from: http://enutrition. fnri.dost.gov.ph/site/uploads/2013_FaF_Biochemical_Survey.pdf

10. Thompson FE, Subar AF. Dietary assessment methodology. In: Coulston AM, Boushey CJ, Ferruzzi MG, Delahanty LM, eds. Nutrition in the Prevention and Treatment of Disease, 4th ed. Academic Press; 2017. pp. 5-48. doi.org/10.1016/B978-0-12-8029282.00001-1

11. Portugal T, Apilado R, Ardeña J, Avena E, Matibag P, Reyes G, et al. The Philippine Food Composition Tables. Food and Nutrition Research Institute, Department of Science and Technology: Manila, Philippines. 1997.

12. Department of Science and Technology - Food and Nutrition Research Institute. Philippine Dietary Reference Intakes (PDRI) [Internet]. 2015 [cited 2020 Jan 4]. Available from https://www.fnri.dost.gov.ph/ images/images/news/PDRI-2018.pdf

13. National Nutrition Council, Department of Health. Philippine Plan of Action for Nutrition 2017-2022 [Internet]. 2017 [cited 2019 Nov 28]. Available from: https://www.nnc.gov.ph/phocadownloadpap/ PPAN/18Sept_PPAN2017_2022Executive\%20Summary.pdf

14. Philippine Statistics Authority and ICF International, Inc. Philippines National Demographic and Health Survey 2017: Key Indicators. Quezon City, Philippines, and Rockville, Maryland, USA. 2018.
15. Adamu Al, Crampin A, Kayuni N, Amberbir A, Koole O, Phiri A, Nyirenda M, Fine P. Prevalence and risk factors for anemia severity and type in Malawian men and women: urban and rural differences. Popul Health Metr. 2017; 15:12. doi.org/10.1186/s12963-017-0128-2

16. Bentley ME, Griffiths PL. The burden of anemia among women in India. Eur J Clin Nutr. 2003 Jan; 57(1):52-60. doi.org/10.1038/ sj.ejcn. 1601504

17. Debelo O, Shiferaw Y. Correlates of Anemia Status Among Women of Reproductive Age in Ethiopia. SSRN 3463707. 2019. doi.org/10.2139/ ssrn.3463707

18. Moor MA, Fraga MA, Garfein RS, Rashidi HH, Alcaraz J, KritzSilverstein D, et al. Individual and community factors contributing to anemia among women in rural Baja California, Mexico. PLoS One. 2017 Nov; 12(11):e0188590. doi.org/10.1371/journal.pone.0188590

19. World Health Organization. Iron with or without folic acid supplementation in women [Internet]. 2019 [cited 2019 Nov 3]. Available from: https://www.who.int/elena/titles/full_recommendations/ifa_ supplementation/en/

20. National Nutrition Council, Department of Health. Why do women need more iron than men? [Internet]. 2017 [cited 2020 Jan 3]. Available from: http://www.nnc.gov.ph/regional-offices/region-vi-westernvisayas/1899-why-do-women-need-more-iron-than-men

21. Aranda N, Ribot B, Garcia E, Viteri FE, Arija V. Pre-pregnancy iron reserves, iron supplementation during pregnancy, and birth weight. Early Hum Dev. 2011 Dec; 87(12):791-7. doi.org/10.1016/ j.earlhumdev.2011.06.003

22. Nestel P. Strategies, Policies and Programs to Improve the Nutrition of Women and Girls [Internet]. 2000 [cited 2019 Dec 27]. Available from: https://reliefweb.int/sites/reliefweb.int/files/resources/7C9F28E A4186E26AC1257410003A3D48-fanta_jan2000.pdf 